\title{
The Role of Learning Strategies for Performance in Mathematics Courses for Engineers
}

Michael Liebendörfer ${ }^{1}$, Lara Gildehaus ${ }^{1}$, Robin Göller ${ }^{2}$, Jörg Kortemeyer ${ }^{3}$, Rolf Biehler $^{1}$, Reinhard Hochmuth ${ }^{4}$, Laura Ostsieker ${ }^{5}$, Jana Rode ${ }^{6}$, Niclas Schaper ${ }^{7}$

${ }^{1}$ Universität Paderborn, Institut für Mathematik, Germany, michael.liebendoerfer@math.upb.de; ${ }^{2}$ Leuphana Universität Lüneburg, Institut für Mathematik und ihre Didaktik, Germany, ${ }^{3}$ Technische Universität Clausthal, Institut für Mathematik, Germany, ${ }^{4}$ Leibniz Universität Hannover, Institut für Didaktik der

Mathematik und Physik, ${ }^{5}$ Technische Hochschule Köln, Institut für

Produktentwicklung und Konstruktionstechnik, ${ }^{6}$ Universität Kassel, Institut für

Mathematik, ${ }^{4}$ Universität Paderborn, Institut für Humanwissenschaften

We analyse the impact of learning strategies on engineering students' performance in mathematics. Learning strategies play an important role in self-regulated learning and are a possible predictor of student performance. Especially for mathematics-related learning strategies, the question arises how such strategies can be measured and how they relate to mathematics performance. Therefore, we present a new learning strategy questionnaire that takes into account the specifics of mathematical learning at universities. We then present correlational data of a longitudinal study with $n=403$ engineering students. We further regress their performance on students' use of their learning strategies as well as their prior performance. The results indicate which learning strategies help students succeed.

Keywords: Teachers' and students' practices at university level, Teaching and learning of mathematics for engineers, Learning strategies, Students' performance.

\section{INTRODUCTION}

Mathematics is still a big hurdle for many students entering university across different study programs. Heublein (2014) reports that at German universities, $36 \%$ of all bachelor-students in engineering drop out and the most prominent reason for drop-out is their problematic performance. Improving students' performance is not only important with regard to drop out but can rather be seen as the major goal of university teaching.

One variable to explain students' performance is their use of strategies. The learning of mathematics at universities usually involves many self-study phases in which students have to self-regulate their learning. However, we lack a clear understanding of what strategies should be recommended and what strategies explain performance, especially when it comes to mathematics courses for engineering students. Only few studies have used instruments that take the characteristics of university mathematics into account and many results are based on cross-sectional but not longitudinal data.

Liebendörfer et al. (submitted) have developed the LimSt questionnaire (Learning strategies in mathematical studies) to measure students' learning strategies specifically 
in higher mathematics. They showed that several strategies could be empirically discerned. The question of how these strategies explain students' performance is still open. In this paper, we use these strategies to predict performance.

\section{THEORETICAL BACKGROUND}

\section{Learning strategies}

Students' use of learning strategies is usually framed within self-regulated learning (Pintrich, 1999) and examined with questionnaires like the "Motivated Strategies for Learning Questionnaire" (MSLQ; Pintrich, Smith, Duncan, \& McKeachie, 1993) or the German adaption "Inventar zur Erfassung von Lernstrategien" (LIST; Schiefele \& Wild, 1994). These questionnaires operationalize cognitive and resource management strategies. They also include metacognitive strategies, which we do not focus in this paper. Cognitive strategies are strategies for the processing of information. The MSLQ distinguishes rehearsal strategies (such as repeating words or other items to remember them) elaboration strategies (such as paraphrasing or summarizing to build internal connections between items), organization (such as outlining or clustering to select appropriate information) and critical thinking (Pintrich et al., 1993). Resource management strategies regulate the use of internal resources, such as time and effort management, and external resources, such as peer learning and help seeking.

University mathematics, however, has some specialties that lead some researchers to either use only parts of the general instruments (e.g., Griese, 2017 dropped the scale for critical checks from the LIST) or completely design new scales (e.g., Kaspersen, 2015 developed a new scale on working conceptionally with mathematics).

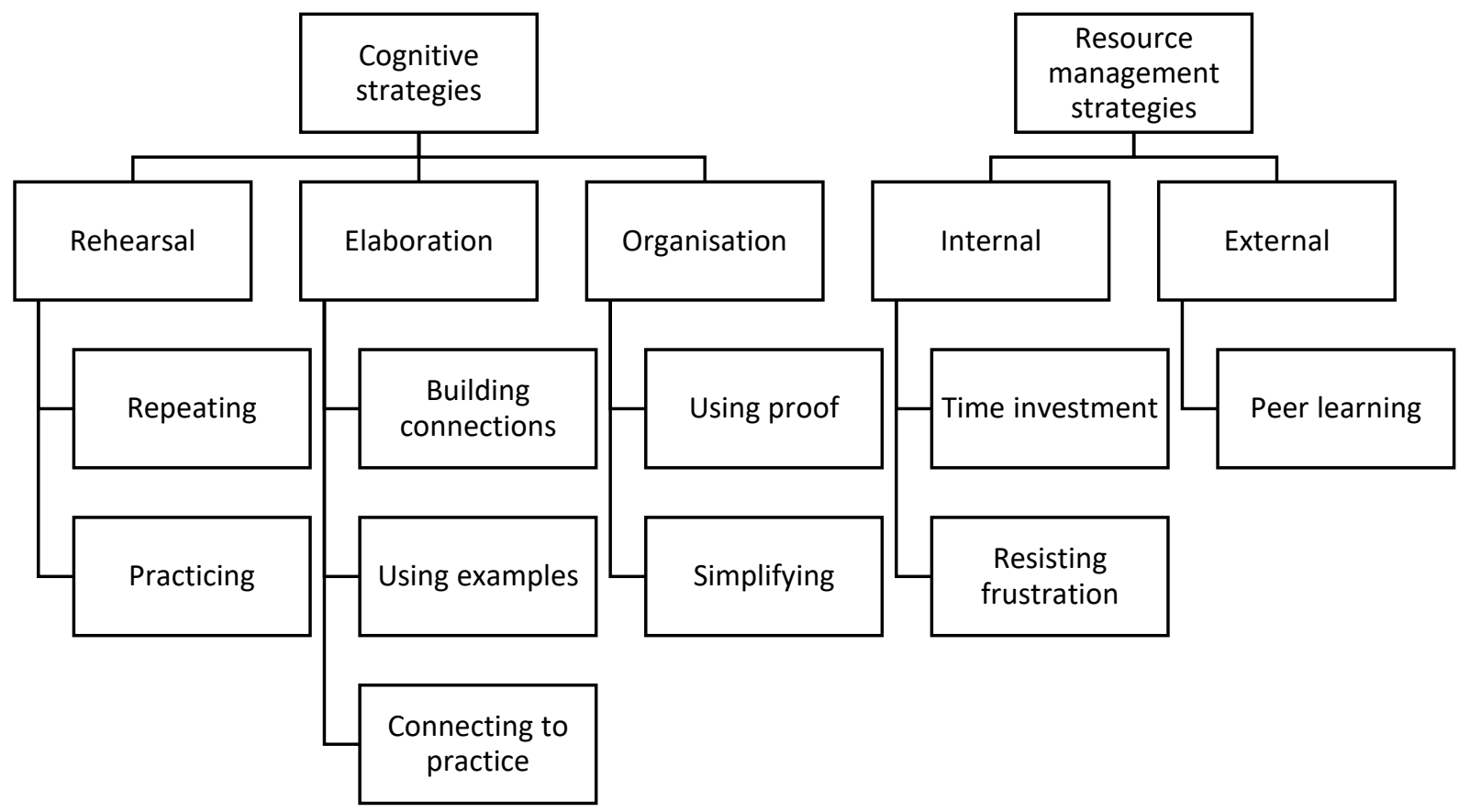

Figure 1: Structure of the LimSt scales used for this research 
Important specifics of university mathematics are the multifaceted role of proof (Auslander, 2008; Jones, 2000; Weber, 2014) and the role of procedural knowledge, e.g. in performing calculations (Bergsten, Engelbrecht, \& Kågesten, 2017; Hiebert, 2013). To address the specialties of university mathematics, Liebendörfer et al. (submitted) developed an instrument similar to the LIST and MSLQ that adds and differentiates more forms of learning strategies to cover these specifics of mathematics.

\section{The LimSt questionnaire}

The LimSt questionnaire (Fragebogen zur Erhebung von Lernstrategien im mathematikhaltigen Studium; Liebendörfer et al., submitted) maintains the distinction between cognitive and resource management strategies, as well as the subdivision in rehearsal, elaboration, organisation strategies, internal and external resources respectively, see Figure 1. However, these strategies have been refined with regard to the specifics of mathematics at the tertiary level. Item examples are given in Table 1.

Rehearsal strategies may refer to the repeated reading, writing or saying aloud of content to be learned. For the learning of mathematics, the rehearsal strategy of practicing is also relevant, which refers to carrying out procedures and algorithms in various examples in order to learn how to perform them. The difference between repeating and practicing strategies is not necessarily due to the content to be learned, since one could also learn about procedures by repeating, e.g. saying aloud the steps in their order. However, practicing is considered necessary for the acquisition of procedural knowledge.

With regard to the elaboration strategies, building connections includes comparing content, relating it to content already learned and finding analogies. For mathematics, two specific forms of connections are particularly relevant. The first form is the use of mathematical examples to illustrate general rules and phenomena or constructions and procedures. The second form refers to the establishing of real-world connections, e.g. via mathematical modelling.

Organization strategies were subdivided in the use of proofs and the simplifying of contents. Using proof refers to any activity that includes the proofs given in lectures or learning materials. Although proof is the central organizing principle of academic mathematics, students often focus on facts and procedures only (Göller, in press). The strategy of simplifying refers to transformations of complex content into less complex forms, even if they are not perfectly correct, like essential ideas that can be memorized more easily.

Resource management strategies include the management of inner resources like students' effort. Whereas effort is often described in terms of time investment, we discern pure time investment from resisting frustration during the learning, which refers to different inner resources like volition or self-control. Finally, peer learning makes use of peers as external resources, like seeking help or collaborating in solving tasks. 


\section{Learning strategies and performance}

The driving motive for the development of theories of learning strategies is the assumption, that different ways of learning may explain different results, in particular differences in students' performance. Students who tend to use some but not other strategies may thus tend learn the content to more effectively. In the literature, some studies on learning strategies and their connection to student performance in service mathematics can be found. We complement our review by the meta-analysis of Schneider and Preckel (2017).

Correlational data show positive connections of working on exercises (focusing procedural knowledge) with performance in exams (Eley \& Meyer, 2004). Since working on exercises can be seen as following a surface approach, this may explain, why although surface learning is generally related to minor success in higher education (Schneider \& Preckel, 2017), this is only sometimes the case for mathematics (Griese \& Kallweit, 2017), but sometimes not (Laging \& Voßkamp, 2017; Liston \& O’Donoghue, 2009).

Theoretically, elaboration strategies are expected to improve study performance because they lead to deep processing of the information, which should lead to deep and stable knowledge. Correlational data show connections of gaining an overview (i.e., using elaboration strategies) with performance in one study on mathematics (Eley \& Meyer, 2004); however, this connection could not be confirmed in several other studies (Griese, 2017; Griese \& Kallweit, 2017; Laging \& Voßkamp, 2017; Liston \& O’Donoghue, 2009; see also Schneider \& Preckel, 2017 for results across different domains). Similarly, organization strategies do not correlate with students' performance (Griese, 2017).

Students' management of internal resources (effort) is an important predictor of academic performance both across different domains (Schneider \& Preckel, 2017) and in university mathematics (Griese, 2017). In contrast, peer learning as a form of managing external resources has proven helpful in various domains (Schneider \& Preckel, 2017) but not mathematics (Griese, 2017).

In sum, these findings from studies of service mathematics show that students' effort is the only strategy having a consistent connection to their performance. We should note, however, that except for the study by Laging und Voßkamp (2017), the presented findings were not based on longitudinal data that include a measure of prior performance, which is generally known to explain much of the future performance (Schneider \& Preckel, 2017). Since there are no earlier studies on the relation of the LimSt scales and students' performance, it is an open question, whether the more specific scales may reveal that specific strategies predict students' performance. 


\section{Research Questions}

Given the new LimSt scales and the few results from longitudinal studies that take students' prior performance into account, we want to explore the connections of students' learning strategy use to their performance. We have two research questions:

RQ1: Which learning strategies correlate with students' performance?

RQ2: Which learning strategies predict students' performance?

\section{METHOD}

We draw on data gathered in summer 2015 in a second-semester course on mathematics for engineers at the University of Hanover (Germany) that follows a firstsemester mathematics course. The cohort consists of students from electrical engineering, civil engineering, mechanical engineering and similar programs. The topics of the first-semester course included analytic geometry, complex numbers, linear algebra (as far as eigenvalues) and univariate analysis (sequences and series, differentiation and integration). In the second semester, multivariate analysis up to integral theorems and ordinary differential equations followed.

In both the course on mathematics in semester 2 and its preceding course in semester 1 , students were offered to take four short exams spread over the semester that replace the final exam at the end of the semester (that still was offered). In each short exam, students could reach up to 10 points, so the possible maximum score is 40 . The pass mark was 15 points and higher results yielded better grades. We use the sum of the four short exams in semester 1 as indicator of students' prior performance and the sum of the four short exams in semester 2 as their performance in the second-semester course.

The tasks focused mainly on calculations. Examples from the four short exams in the second semester are to investigate the convergence of power series, to give Taylor polynomials for given functions in one and two dimensions, to find extreme values, to calculate line integrals or to solve differential equations. In contrast, no task required proof. Students were not allowed to bring their notes or calculators.

Students were further asked to answer a paper and pencil questionnaire during lecture time. We measured their learning strategies on Likert scales from the LimSt questionnaire described above ranging from 1 (strongly disagree) to 6 (strongly agree). Most of them were newly developed, only the time investment scale consists of four items of the LIST scale for effort (Schiefele \& Wild, 1994) that focuses on time investment, supplemented by one more item, see (Liebendörfer et al., submitted) for details to all scales. All scales showed a high internal consistency, see Table 1.

The learning strategies were assessed at the beginning of the course, so the students answered the questionnaire after having completed all short exams that measure their prior performance and prior to the short exam measuring their future performance. We analyse the data of the subgroup of all engineering students (more than 1000) who had 
taken the short exams and agreed on sharing their results $(n=403 ; 93 \%$ were in their second semester, $77 \%$ were male).

Both the questionnaire data and the short exam results were treated as metric data in the analysis; i.e. we give means and standard deviations and use Cronbach alpha and Pearson correlations as well as a linear regression analysis. This treatment may not perfectly match the ordinal data given, but is simple and seems to yield appropriate results. The methods are well known in the field and questionnaire data is often handled similarly.

\section{RESULTS}

Before answering the research questions, we give mean values and standard deviations in Table 1. The mean values show that students strongly report the use of the rehearsal strategies practicing and repeating as well as peer learning. In contrast, using proof is the strategy with the lowest mean, but highest standard deviation.

\section{Correlations}

To answer RQ1, we report the correlations of prior performance, performance and learning strategies in Table 1. The two rehearsal strategies repeating and practicing have positive correlations with performance. Of the elaboration strategies, only building connections has positive correlations to performance. Of the organization strategies, only using proof has a small positive correlation to prior performance. The two forms of effort, time investment and resisting frustration both show positive correlations to performance and peer learning has a small correlation to future performance. Note that generally, the correlations with prior performance and future performance are almost equal.

\section{Regression analysis}

To answer RQ2, we conducted a linear regression using all learning strategies and the prior performance as predictors of future performance. Together, these variables could explain $57 \%$ of the variance of future performance $\left(\mathrm{R}^{2}=.57\right)$. The non-standardized regression coefficients are displayed in Table 1. Prior performance is a clear predicator of future performance. Of the rehearsal strategies, repeating is a negative predictor, whereas practicing is a positive predictor. None of the elaboration strategies predicted performance. Of the organization strategies, simplifying is a negative predicator. Resisting frustration but not time investment predicts performance and finally peer learning does not predict performance. 


\begin{tabular}{|c|c|c|c|c|c|c|c|c|}
\hline & Item example & Items & $\alpha$ & M & SD & $\mathrm{r}_{\mathrm{PP}}$ & $\mathrm{r}_{\mathrm{P}}$ & b \\
\hline $\begin{array}{l}\text { Prior } \\
\text { Performance }\end{array}$ & & & & 19.02 & 8.18 & & & 0.71 \\
\hline Performance & & & & 15.81 & 8.71 & .73 & & -- \\
\hline Repeating & $\begin{array}{l}\text { I repeatedly go through } \\
\text { important content so that I } \\
\text { will not forget it. }\end{array}$ & 3 & .74 & 4.49 & 0.84 & .21 & .14 & -1.35 \\
\hline Practicing & $\begin{array}{l}\text { I learn algorithms by } \\
\text { repeatedly performing the } \\
\text { procedure. }\end{array}$ & 3 & .77 & 4.43 & 1.16 & .24 & .23 & 0.66 \\
\hline $\begin{array}{l}\text { Building } \\
\text { connections }\end{array}$ & $\begin{array}{l}\text { I try to understand how } \\
\text { new content relates to what } \\
\text { I have learned before. }\end{array}$ & 4 & .82 & 3.99 & 0.98 & .24 & .21 & 0.26 \\
\hline $\begin{array}{l}\text { Using } \\
\text { examples }\end{array}$ & $\begin{array}{l}\text { I search for application } \\
\text { examples for formulas. }\end{array}$ & 4 & .77 & 3.89 & 0.97 & .06 & .07 & -0.02 \\
\hline $\begin{array}{l}\text { Connecting } \\
\text { to practice }\end{array}$ & $\begin{array}{l}\text { I think about what one can } \\
\text { practically do with new } \\
\text { content. }\end{array}$ & 3 & .74 & 3.20 & 1.30 & -.08 & -.02 & 0.29 \\
\hline Using proof & $\begin{array}{l}\text { I try to understand the } \\
\text { proofs of the theorems. }\end{array}$ & 3 & .85 & 3.14 & 1.33 & .12 & .10 & -0.11 \\
\hline Simplifying & $\begin{array}{l}\text { I try to simplify difficult } \\
\text { content. }\end{array}$ & 3 & .75 & 4.36 & 0.93 & .03 & -.04 & -0.76 \\
\hline $\begin{array}{l}\text { Time } \\
\text { investment }\end{array}$ & $\begin{array}{l}\text { I take more time for } \\
\text { learning than most of my } \\
\text { peers. }\end{array}$ & 5 & .79 & 4.15 & 1.01 & .28 & .29 & 0.21 \\
\hline $\begin{array}{l}\text { Resisting } \\
\text { frustration }\end{array}$ & $\begin{array}{l}\text { I do not give up, even if the } \\
\text { content is very difficult or } \\
\text { complicated. }\end{array}$ & 3 & .79 & 4.15 & 1.13 & .34 & .40 & 1.47 \\
\hline $\begin{array}{l}\text { Peer } \\
\text { learning }\end{array}$ & $\begin{array}{l}\text { I meet with fellow students } \\
\text { to develop ideas for } \\
\text { solutions together. }\end{array}$ & 3 & .78 & 4.48 & 1.23 & .09 & .13 & 0.35 \\
\hline
\end{tabular}

Table 1: Example item, Cronbach's Alpha, mean (M), and standard deviation (SD) for students' performance and the learning strategies measured, as wells as correlation coefficients for prior performance ( $\left.r_{P P}\right)$ and performance ( $\left.r_{p}\right)$ and the nonstandardized regression coefficient (b) for performance regressed on prior performance and learning strategies. Coefficients significant at $p<.05$ are in italics, they are bold if $\mathrm{p}<.01$. 


\section{DISCUSSION}

Based on a refined scale on learning strategies for mathematics and a longitudinal sample of engineering students, we investigated the relationship between performance and learning strategy use.

Besides the significant and high correlation of performance and prior performance, the correlation analysis showed that the rehearsal strategies of repeating and practicing, the strategy of building connections, and the scales for time investment and resisting frustration showed high correlations to performance. It may seem surprising, however, that stronger students put much of their effort into rehearsal strategies that are often labelled surface strategies but not most of the elaboration and organization strategies. This result can be understood if we consider the kind of mathematics that was requested in the short exams, which is mainly procedural knowledge.

The regression analysis showed that performance could mainly be explained by prior performance confirming the literature (Schneider \& Preckel, 2017). Yet, some of the learning strategies can explain further parts of students' performance. The rehearsal strategies practicing and repeating both are significant predictors. Surprisingly, while practicing is a positive predictor, repeating is a negative predictor. Of course, a negative coefficient does not mean here that a specific form of learning does not help the individual but that students who used this strategy learned less than the average of the student cohort, so the strategy may be effective but not efficient. This finding highlights the constructivist view that mathematics is an activity and learning mathematics means doing mathematics. From the elaboration strategies, only simplifying, which was highly used by students, is a significant (negative) predictor for performance. Whereas simplifying could help students to get a rough overview of a topic, it seems as if they do not get deeper into the content. From the internal resource management strategies, only resisting frustration is a (positive) predictor of performance.

Comparing correlations and regression results, we see that repeating is something that rather good students do but does not help them getting better. Similarly, stronger students use proofs more often but that does not explain future performance. This fits the general consideration that the knowledge required in written exams can be mostly achieved through practicing strategies. In addition, stronger students invest more time, but that does not explain their performance. The quality of students' learning may thus be more important than the quantity of their time invested.

Our conclusion is that performance is raised by practicing but not repeating, and by resisting frustration but not simplifying. Doing the hard and frustrating work pays off.

\section{Strengths and limitations}

The strengths of our study encompass using a validated instrument that was specifically designed for higher mathematics, relying on longitudinal data in a large cohort taking into account prior performance, and a high ecological validity by using exam scores. This allowed revealing differences in related variables like repeating and practicing or 
time investment and resisting frustration that can be clearly linked to engineering students' performance in exams.

Limitations include that we only analysed a subset of students that may have their specialties. Further, questionnaire data do not perfectly represent real behaviour and testing at the beginning of the semester does not cover later changes in students' learning behaviour. This may have blurred some results. In addition, the exams we used as a measure of students' performance focus on procedural knowledge. We should therefore limit our findings to the learning of procedural mathematics.

\section{Implications for theory and practice}

Besides the identification of relevant learning strategies, our theoretical differentiation of the individual mathematics-related learning strategies built a useful frame. In particular, rehearsal and effort were split into forms with different roles as predictors. Future research could explore the role of these refined strategies for the learning of other forms of mathematics, e.g. in teacher education. The longitudinal design further revealed that correlational patterns do not need longitudinal patterns so we should not take correlations of learning strategies as indicator of causality (see repeating or using proof).

Our recommendation for students' learning is to practice mathematics and work hard but not simplify and repeat (as many do according to the mean values).

\section{REFERENCES}

Auslander, J. (2008). On the roles of proof in mathematics. In B. Gold \& R. A. Simons (Eds.), Proof and other dilemmas: Mathematics and philosophy (pp. 61-77). Washington, D.C.: Mathematical Association of America.

Bergsten, C., Engelbrecht, J., \& Kågesten, O. (2017). Conceptual and Procedural Approaches to Mathematics in the Engineering Curriculum - Comparing Views of Junior and Senior Engineering Students in Two Countries. EURASIA Journal of Mathematics, Science and Technology Education, 13(3). https://doi.org/10.12973/eurasia.2017.00631a

Eley, M. G., \& Meyer, J. H. F. (2004). Modelling the influences on learning outcomes of study processes in university mathematics. Higher Education, 47(4), 437-454.

Göller, R. (in press). Selbstreguliertes Lernen im Mathematikstudium-Eine qualitative Studie zur Beschreibung und Erklärung der Lern- und Problemlösestrategien von Mathematikstudierenden im ersten Studienjahr mithilfe ihrer Ziele, Beliefs und Bewertungen. Wiesbaden: Springer Fachmedien Wiesbaden.

Griese, B. (2017). Learning Strategies in Engineering Mathematics. Wiesbaden: Springer Fachmedien Wiesbaden. https://doi.org/10.1007/978-3-658-17619-8

Griese, B., \& Kallweit, M. (2017). Engineering mathematics between competence and calculation. In Dooley, T. \& Gueudet, G. (Eds.) Proceedings of the Tenth Congress of the European Society for Research in Mathematics Education (CERME10, 
February 1-5, 2017) (pp. 2139-2136). Dublin, Ireland: DCU Institute of Education \& ERME. Retrieved from https://hal.archives-ouvertes.fr/hal-01941344/document

Heublein, U. (2014). Student Drop-out from German Higher Education Institutions. European Journal of Education, 49(4), 497-513. https://doi.org/10.1111/ejed.12097

Hiebert, J. (2013). Conceptual and Procedural Knowledge: The Case of Mathematics. New York; London: Routledge.

Jones, K. (2000). The student experience of mathematical proof at university level. International Journal of Mathematical Education in Science and Technology, 31(1), 53-60. https://doi.org/10.1080/002073900287381

Kaspersen, E. (2015). Using the Rasch Model to Measure the Extent to which Students Work Conceptually with Mathematics. Journal of Applied Measurement, 16(4), 336-352.

Laging, A., \& Voßkamp, R. (2017). Determinants of Maths Performance of First-Year Business Administration and Economics Students. International Journal of Research in Undergraduate Mathematics Education, 3(1), 108-142. https://doi.org/10.1007/s40753-016-0048-8

Liebendörfer, M., Göller, R., Biehler, R., Hochmuth, R., Kortemeyer, J., Ostsieker, L., Rode, J., Schaper, N. (submitted). LimSt - Ein Fragebogen zur Erhebung von Lernstrategien im mathematikhaltigen Studium. Journal Für Mathematik-Didaktik.

Liston, M., \& O'Donoghue, J. (2009). Factors influencing the transition to university service mathematics: Part $1-$ a quantitative study. Teaching Mathematics Applications, 28(2), 77-87.

Pintrich, P. R. (1999). The role of motivation in promoting and sustaining selfregulated learning. International Journal of Educational Research, 31(6), 459-470.

Pintrich, P. R., Smith, D. A. F., Duncan, T., \& McKeachie, W. J. (1993). Reliability and Predictive Validity of the Motivated Strategies for Learning Questionnaire (MSLQ). Educational and Psychological Measurement - EDUC PSYCHOL MEAS, 53, 801-813. https://doi.org/10.1177/0013164493053003024

Schiefele, U., \& Wild, K.-P. (1994). Lernstrategien im Studium: Ergebnisse zur Faktorenstruktur und Reliabilität eines neuen Fragebogens. Zeitschrift Für Differentielle Und Diagnostische Psychologie, 15, 185-200.

Schneider, M., \& Preckel, F. (2017). Variables associated with achievement in higher education: A systematic review of meta-analyses. Psychological Bulletin, 143(6), 565-600. https://doi.org/10.1037/bul0000098

Weber, K. (2014). Proof as a Cluster Concept. In C. Nicol, S. Oesterle, P. Liljedahl, \& D. Allan (Eds.), Proceedings of the 38th Conference of the International Group for the Psychology of Mathematics Education and the 36th Conference of the North American Chapter of the Psychology of Mathematics Education (Vol. 5, pp. 353360). Vancouver: PME. 